\title{
Vegetative Development of Sparassis crispa in Various Growth Conditions and Effect of Electric Pulse Simulation on Its Fruit Body Production
}

\author{
Muhammad Umar Farooq, Alfred Chioza, Shoji Ohga \\ Department of Agro-Environmental Sciences, Faculty of Agriculture, Kyushu University, Fukuoka, Japan \\ Email: ohga@forest.kyushu-u.ac.jp
}

Received 4 March 2014; revised 4 April 2014; accepted 14 April 2014

Copyright (C) 2014 by authors and Scientific Research Publishing Inc.

This work is licensed under the Creative Commons Attribution International License (CC BY). http://creativecommons.org/licenses/by/4.0/

(c) (i) Open Access

\section{Abstract}

This study was carried out to detect the favorable mycelial growth conditions and effect of electric pulse stimulation on fruit body production of SC-1 strain of Sparassis crispa. The optimum growth in PDA was found at $25^{\circ} \mathrm{C}\left(67 \mathrm{~mm}\right.$ colony diameter in 28 days) followed by $20^{\circ} \mathrm{C}(63 \mathrm{~mm}$ colony diameter in 28 days). There was no mycelial growth at $35^{\circ} \mathrm{C}$. The most favourable initial media pH range was found to be 5 - 7 and colony diameter measurements were not statistically different among these $\mathrm{pH}$ values $(\mathrm{p}>\mathbf{0 . 0 5})$. However, the highest growth was obtained at pH $6(57 \mathrm{~mm}$ colony diameter in 28 days). A basal medium composed of $0.05 \mathrm{~g} \mathrm{MgSO}_{4}, 0.46 \mathrm{~g} \mathrm{KH}_{2} \mathrm{PO}_{4}, 1.0 \mathrm{~g} \mathrm{~K}_{2} \mathrm{HPO}_{4}$, $120 \mu \mathrm{g}$ thiamine- $\mathrm{HCl}, 20 \mathrm{~g}$ agar and $1000 \mathrm{ml}$ of distilled water was used to investigate growth response of $S$. crispa to different carbon and nitrogen sources. In 28 days, fructose and glucose exhibited best growth $(49.4 \mathrm{~mm}$ and $31.6 \mathrm{~mm}$ colony diameters respectively) and there was no growth on the basal medium supplemented with galactose. Basal medium supplemented with glycine and alanine as nitrogen sources resulted in best growth, $54.4 \mathrm{~mm}$ and $50.5 \mathrm{~mm}$ colony diameters respectively. There was no mycelial growth in culture medium supplemented with ammonium acetate, ammonium phosphate, arginine and histidine. Electric pulse stimulation improved the fruiting body production. The yields obtained from all bottles in which electric pulse was applied were significantly higher than the yields from the bottles in which electric pulse was not applied. The percent increases of fresh weight yield from control on 100, 120, 130, and 170 kilovolts were $36 \%, 44 \%, 75 \%$ and $81 \%$ respectively. As regard to dry weight yield, the percent increases from control on 100, 120, 130, and 170 kilovolts were $27 \%, 54 \%, 63 \%$ and $67 \%$ respectively. 


\section{Keywords}

\section{Sparassis crispa, Fruit Body Production, Mycelial Growth, Electric Pulse Stimulation}

\section{Introduction}

Sparassis crispa is an edible mushroom with a number of reported medicinal benefits. This fungus is commonly known as cauliflower mushroom because the shape of its fruiting body closely resembles with cauliflower. It is also called brown rot fungi because it causes brown rot and butt rot in living conifers [1]. It is called by different names in different countries. For instance, in France it is called by the names: Clavaire crepue, Morille des pins, Sparassis crepue and Crete de coq; in Germany they call it Feisterling digal; Sheikaosin in China and in Japan "Hanabiratake" and "Hanabiramaitake" because it grows on larch trees [2]. As reported by Kimura [3], the fruit body of S. crispa has about $90 \%$ water and contains $13.4 \mathrm{~g}$ protein, $2.0 \mathrm{~g}$ fat, $21.5 \mathrm{~g}$ carbohydrate, $1.8 \mathrm{~g}$ ash and $61.2 \mathrm{~g}$ dietary fibre per $100 \mathrm{~g}$ of dry weight. This fungus belongs to the phylum; Basidiomycota, class; Agaricomycetes, order; Polyporales, family; Sparassidaceae, genus; Sparassis and species; crispa [3]. The content of $\mathrm{D}_{2}$ Vitamin, that is helpful in intestinal calcium absorption, is about $0.17 \mathrm{mg}$ per $100 \mathrm{~g}$ of dry weight [2]. The results obtained from headspace analysis indicate that 3-octanone, DL-3-octanol, and 1-octen-3-ol contribute to the particular aroma of this mushroom [4]. Medicinal properties in S. crispa include anticancer activities, antiangiogenic, anti-metastatic, wound healing and immune stimulation effects [5]-[7]. It has been recorded that $\beta$-glucan content of $S$. crispa is about $43.6 \%$ as measured by enzyme method by Japan Food research laboratories. Thus, S. crispa can be utilized for mass production of $\beta$-glucan [8]. Kimura [3] reported that the medicinal value of this mushroom is mainly due to 6-branched 1,3-beta-glucan (SCG).

High fruit body yield is one of the major desirable outputs of mushroom cultivation. Among other methods, some researchers have tried to improve the fruit body development and yield of edible mushrooms by application of electric pulse stimulation. For example, Tsukamoto et al. [9] found that the yield of Shiitake from logs to which the pulsed high voltage was applied was twice as much as that from logs in which the pulsed voltage was not applied. Application of high voltages of up to $120 \mathrm{kV}$ in bottle cultivation of Hypsizygus marmoreus and Pleurotus eryngii increased the fruit body yield of these mushrooms by 13 - 15 percent [10]. Islam and Ohga [11] reported a significant increase in fruit body yield of Tricholoma matsutake as a result of applying electric pulse. Having seen that this technology has worked with success in a number of mushrooms, a study was conducted to investigate the effect of electric pulse stimulation on fruit body development and yield of SC-1 strain of $S$. crispa. Prior to this, we also carried out experiments to determine the effect of environmental and nutritional factors on mycelial growth of SC-1 strain of S. crispa.

\section{Materials and Methods}

\subsection{Strain Used}

The strain SC-1 of S. crispa, accession number KUMB 1201 in the Mushroom Culture Bank at the Laboratory of Forest Resource Management, Kyushu University was utilized for this study. This strain was isolated from the fruit body of naturally growing S. crispa in Miyazaki Research Forest of Kyushu University (Figure 1).

\subsection{Effect of Temperature}

To investigate the favourable temperature for optimum mycelial growth of $S$. crispa (SC-1), five different temperatures were tested in PDA medium. The medium was autoclave sterilized for 15 minutes at $121^{\circ} \mathrm{C}$. Soon after sterilization the medium was poured into petri dishes. Each plate was filled with about $25 \mathrm{ml}$ of PDA. Agar plugs ( $5 \mathrm{~mm}$ diameter) with actively growing mycelium were inoculated by placing on the centre of the medium surface in each petri dish. Four inoculated plates were incubated at each of the following temperatures: $15^{\circ} \mathrm{C}$, $20^{\circ} \mathrm{C}, 25^{\circ} \mathrm{C}, 30^{\circ} \mathrm{C}$ and $35^{\circ} \mathrm{C}$. The measurements of radial mycelial growth were done using the method as described by Chioza and Ohga [12]. The diameter of each petri dish was determined by calculating the average of three diameter measurements. 


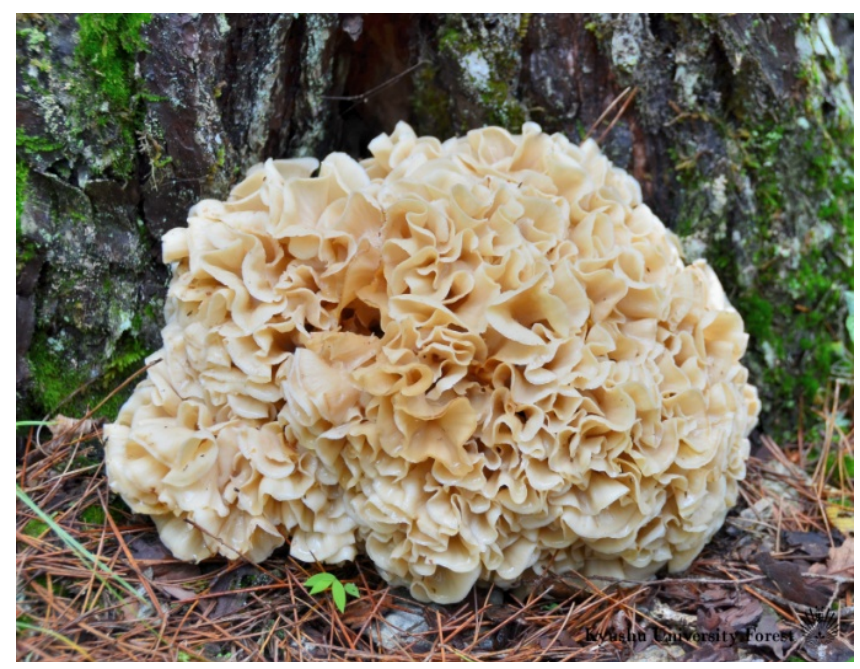

Figure 1. Sparassis crispa growing naturally on a Pinus densiflora base in Miyazaki Research Forest of Kyushu University.

\subsection{Effect of $\mathrm{pH}$}

The PDA medium was prepared in five flasks which were adjusted to $\mathrm{pH} 5,6,7,8$ and 9 before sterilization. The $\mathrm{pH}$ adjustments were made by using $1 \mathrm{~N} \mathrm{NaOH}$ or $\mathrm{HCl}$. After autoclaving for 15 minutes at $121^{\circ} \mathrm{C}$, media were poured into petri dishes with about $25 \mathrm{ml}$ of PDA each. Agar plugs (5 mm diameter) with actively growing mycelium of S. crispa (SC-1) were inoculated on the plates as described earlier. Inoculated petri dishes were incubated for 28 days at $25^{\circ} \mathrm{C}$. The measurement of mycelial growth was made using the method explained above.

\subsection{Screening of Carbon Source}

To investigate the favorable carbon source(s) for mycelia growth of S. crispa (SC-1), experiment was conducted by using a basal medium along with 10 carbon sources namely fructose, glucose, lactose, galactose, maltose, mannose, sorbitol, sucrose, xylose and xylitol. The basal medium was composed of $0.05 \mathrm{~g} \mathrm{MgSO}_{4}, 0.46 \mathrm{~g}$ $\mathrm{KH}_{2} \mathrm{PO}_{4}, 1.0 \mathrm{~g} \mathrm{~K} \mathrm{HPO}_{4}, 120 \mu \mathrm{g}$ thiamine-HCL, $20 \mathrm{~g}$ agar and $1000 \mathrm{ml}$ distilled water. Each carbon source, together with $5 \mathrm{~g}$ of peptone, was added to the basal medium at the concentration of $0.1 \mathrm{M}$ [13]. The media were sterilized for 15 minutes at $121^{\circ} \mathrm{C}$ before inoculating each plate with agar plugs ( $5 \mathrm{~mm}$ diameter). The plates were then incubated at $25^{\circ} \mathrm{C}$ for 28 days. On the $28^{\text {th }}$ day after incubation colony diameters were measured. Diameter for each plate was recorded as an average of three diameter measurements [12].

\subsection{Screening of Nitrogen Sources}

The basal medium used for screening nitrogen sources was the same used for screening the carbon sources. The following 10 nitrogen sources were tested: alanine, urea, glycine, calcium nitrate, potassium nitrate, methionine, histidine, arginine, ammonium phosphate and ammonium acetate. Each nitrogen source was added with $20 \mathrm{~g}$ of glucose to the basal medium at the concentration of $0.02 \mathrm{M}$ as described by Shim et al. [14]. The basal medium was adjusted to $\mathrm{pH} 6$ before autoclaving at $121^{\circ} \mathrm{C}$ for 15 minutes. All petri dishes were incubated for 28 days at $25^{\circ} \mathrm{C}$. On the $28^{\text {th }}$ day after incubation, colony diameters were measured as explained earlier.

\subsection{Electric Pulse Stimulation}

\subsubsection{Culture Media and Growth Conditions}

Bottle cultivation method was used in fruit body production of S. crispa. Each bottle contained $700 \mathrm{~g}$ of substrate (larch sawdust, wheat bran and corn powder in the ratio 5:1:1). The medium was sterilized by autoclaving at $120^{\circ} \mathrm{C}$ for 30 minutes and then cooled down to room temperature. The sawdust spawn was inoculated by spreading evenly on the surface of the substrate in the bottle. The inoculated bottles were then incubated at $25^{\circ} \mathrm{C}$, in the dark, until full colonisation. In order to induce fruit body formation, kinkaki treatment (removal of spawn 
and the uppermost part of the medium) followed by chilling procedure were applied.

\subsubsection{Electric Pulse Treatment}

Electric pulse treatments were applied immediately after exposing the fully colonised bottles to chilling. Pulsed power voltages of 100, 120, 130 and 170 kilovolts were directly applied through the electrodes from the instrument to the fully colonised substrate in the bottles. The instrument (YH1G-200K-1KJC) used was manufactured by Yamabishi Electric Co. Ltd., Japan.

\subsection{Data Analysis}

Determination of statistical differences was done by Analysis of Variance (ANOVA) followed by Tukey's test ( $\mathrm{p}<0.05$ ). Minitab 16 statistical software (Minitab Inc.) was used to perform the analyses. Data in all tables is presented as mean plus or minus standard deviation.

\section{Results and Discussion}

\subsection{Effect of Temperature}

The most suitable temperature for mycelial growth of S. crispa was found to be $25^{\circ} \mathrm{C}$ (Figure 2). This temperature is reported as the most favourable for the majority of mushrooms which include Coprinus comatus [15], Paecilomyces hepiali [12], Paecilomyces fumosoroseus [14] [16], Ophiocordyceps heteropoda [17] and Cordyceps cardinalis [18]. The next favourable temperature was $20^{\circ} \mathrm{C}$. Cheong [19] reported $23^{\circ} \mathrm{C}$ as the optimum temperature for mycelial growth of $S$ crisp. This finding is within the favourable range $\left(20^{\circ} \mathrm{C}-25^{\circ} \mathrm{C}\right)$ obtained in this study. Shim et al. [1] reported that mycelial growth of $S$. crispa decreased with temperatures above $25^{\circ} \mathrm{C}$. That is similar to the findings of this study. At $30^{\circ} \mathrm{C}$ growth was considerably slow (Figure 2) and there was no growth at $35^{\circ} \mathrm{C}$. Apart from few mushrooms such as Volvariella volvacea [20] and Macrolepiota procera [21], the majority do not have mycelial growth at temperatures beyond $30^{\circ} \mathrm{C}$. Denaturation of important ezymes which catalyse fungal metabolic processes may be the main reason for not having any growth at $35^{\circ} \mathrm{C}$ [22].

\subsection{Effect of $\mathrm{pH}$}

This study shows that slightly acidic to neutral initial agar media $\mathrm{pH}$ is most favourable for mycelial growth of $S$. crispa (Figure 3 and Figure 4). The PDA medium with initial $\mathrm{pH}$ of 6 resulted in highest mycelial growth among the $\mathrm{pH}$ levels tested (pH 5 - 9). However, mycelial growth measurements within the initial $\mathrm{pH}$ range 5 - 7 were not statistically different. The colony morphological characteristics among this $\mathrm{pH}$ range were also quite similar (Figure 4). This study confirms the finding by Cheong [19] in terms of the most favourable initial media

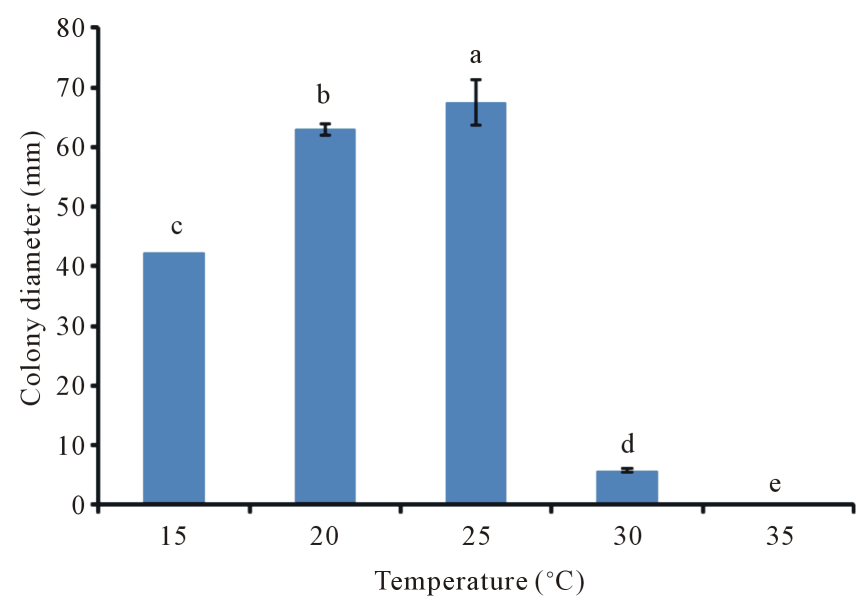

Figure 2. Mycelial growth of S. crispa at different temperatures in 28 days. Graph bars with different letters at the top represent values that are significantly different according to Tukey's Test $(\mathrm{p}<0.05)$. The error bars represent standard error. 


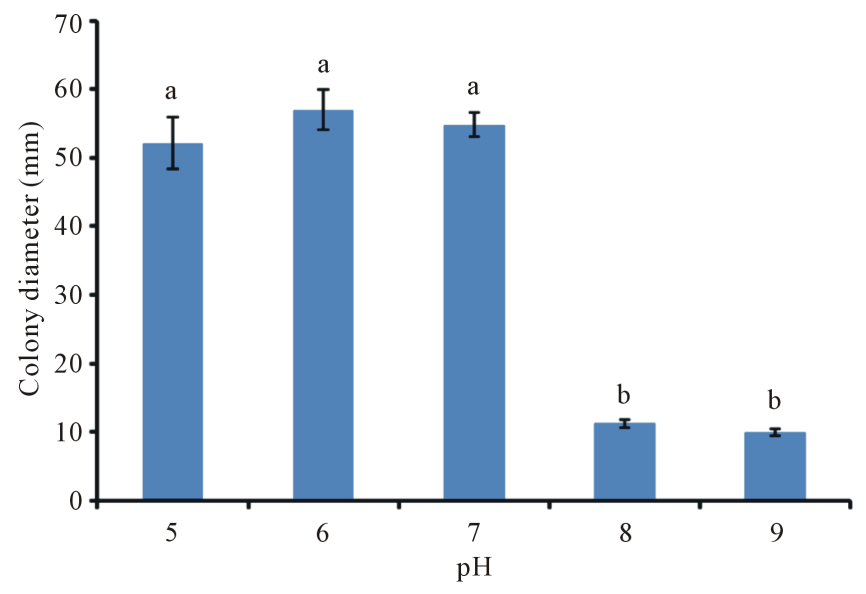

Figure 3. Mycelial growth of $S$. crispa at different $\mathrm{pH}$ levels on $28^{\text {th }}$ day (Incubation temperature: $25^{\circ} \mathrm{C}$ ). Graph bars with different letters at the top represent values that are significantly different according to Tukey's Test $(\mathrm{p}<0.05)$. The error bars represent standard error.
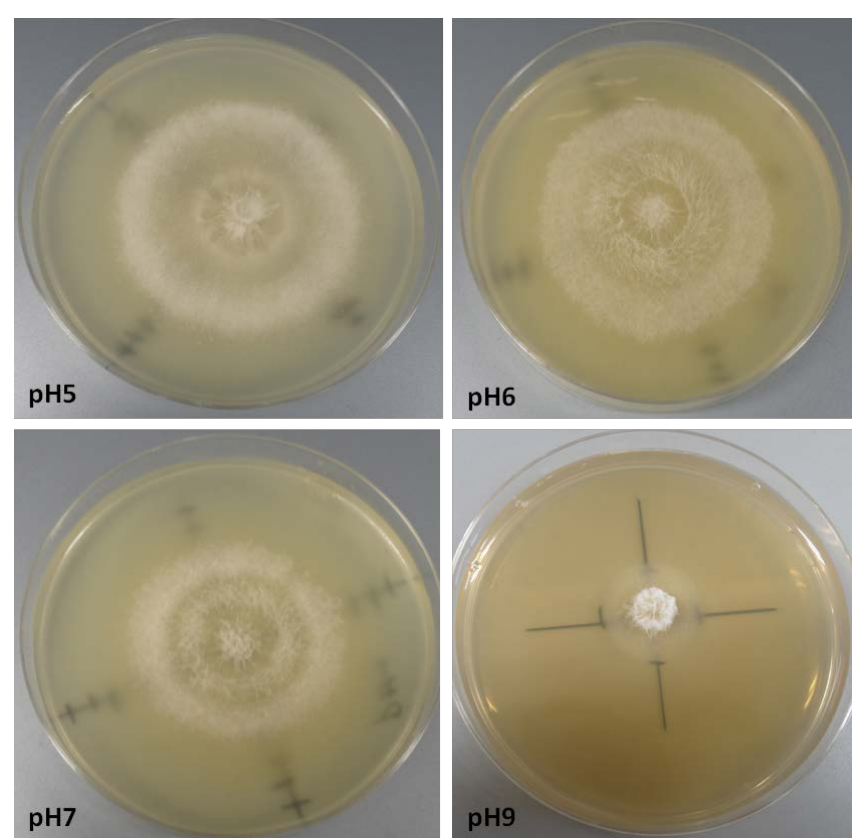

Figure 4. Colonies of S. crispa after 28 days of mycelial growth in media with different initial $\mathrm{pH}$ levels (Incubation temperature: $\left.25^{\circ} \mathrm{C}\right)$.

$\mathrm{pH}$ for mycelial growth of S. crispa. In media with initial $\mathrm{pH}$ levels beyond 7, there was a sharp decline in mycelial growth. This indicates that this fungus does not favour media with alkaline initial $\mathrm{pH}$.

\subsection{Effect of Carbon Source}

In order to determine suitable carbon sources for mycelial growth of $S$. crispa, ten different carbon sources were tested. Among them, fructose followed by glucose supported the best mycelial growth (Table 1). The most unsuitable carbon source was galactose which supported no mycelial growth at all (Table 1). The colony diameter measurements from fructose and glucose, $36.9 \pm 1.9 \mathrm{~mm}$ and $31.6 \pm 6.8 \mathrm{~mm}$ respectively, were statistically the same and significantly much higher than the rest of the carbon sources which supported no more than $6.9 \mathrm{~mm}$ of 
Table 1. Effect of carbon sources on mycelial growth of S. crispa in the basal medium.

\begin{tabular}{cc}
\hline Carbon Source & Colony diameter $(\mathrm{mm})$ \\
\hline Fructose & $36.9 \pm 1.9 \mathrm{a}$ \\
Galactose & $0.0 \pm 0.0 \mathrm{~b}$ \\
Glucose & $31.6 \pm 6.8 \mathrm{a}$ \\
Lactose & $5.8 \pm 0.2 \mathrm{~b}$ \\
Maltose & $6.8 \pm 0.6 \mathrm{~b}$ \\
Mannose & $5.0 \pm 0.0 \mathrm{~b}$ \\
Sorbitol & $6.9 \pm 0.2 \mathrm{~b}$ \\
Sucrose & $6.2 \pm 0.2 \mathrm{~b}$ \\
Xylitol & $6.5 \pm 0.5 \mathrm{~b}$ \\
Xylose & $6.8 \pm 0.6 \mathrm{~b}$ \\
\hline
\end{tabular}

Colony diameter values that do not share a letter are significantly different according to Tukey's Test ( $\mathrm{p}$ 0.05). The basal medium was composed of $0.05 \mathrm{~g} \mathrm{MgSO}_{4}, 0.46$ g $\mathrm{KH}_{2} \mathrm{PO}_{4}, 1.0 \mathrm{~g} \mathrm{~K}_{2} \mathrm{HPO}_{4}, 120 \mu \mathrm{g}$ thiamine-HCl, $20 \mathrm{~g}$ agar and $1000 \mathrm{ml}$ distilled water. Each carbon source was added to the basal medium at the concentration of 0.1 M. The colony diameter was measured after 28 days of mycelial growth.

colony diameter growth in 28 days. This study shows that this fungus has preference for simple monosaccharides. The reason could be that they can be easily absorbed and metabolized during cellular respiration. Our finding differs with that of Shim et al. [1] on galactose for the same mushroom. They reported growth of about $7.6 \mathrm{~mm} / 15$ days on galactose as carbon source while in this study no growth was observed on the same.

\subsection{Effect of Nitrogen Source}

Out of the ten nitrogen sources tested, the most favourable was found to be glycine followed by alanine (Table 2). Shim et al. [1] also found the highest mycelial growth of S. crispa when cultural media was supplemented with glycine. There was no growth in media with histidine, arginine, ammonium phosphate and ammonium acetate as nitrogen sources. This is in agreement with findings of Shim et al. [1] on ammonium acetate and histidine. However, on arginine and ammonium phosphate the results differ in that they found mycelial growth when these compounds were used as nitrogen sources. In our study urea supported some mycelial growth whereas Shim et al. [1] observed no growth with the same compound. This may be due to differences in the strains used.

\subsection{Effect of Electric Pulse Stimulation}

Results showed that an electric pulse has a significant effect on fruit body yield of S. crispa. As the voltage increased, the fruit body yield also increased (Figure 5). In the case of dry weight yield, it was observed that it increased more with the increase in voltage of the electric pulse between zero and $120 \mathrm{kV}$ than between $120 \mathrm{kV}$ and $170 \mathrm{kV}$. Fresh weight yield increased more with the increase in voltage between zero and $130 \mathrm{kV}$ of electric pulse than between $130 \mathrm{kV}$ and $170 \mathrm{kV}$. The highest yield was found at $170 \mathrm{kV}$ of electric pulse. There was more primodia on substrate treated with electric pulse as compared to control. The percent increases of fresh weight yield from control on 100, 120, 130, and 170 kilovolts were $36 \%, 44 \%, 75 \%$ and $81 \%$ respectively. As regard to dry weight yield, the percent increases from control on 100,120, 130, and 170 kilovolts were $27 \%$, $54 \%, 63 \%$ and $67 \%$ respectively. Takaki et al. [23] reported $86 \%$ increase in the production of $L$. edodes by applying electric pulse. Two possible explanations have been reported for the increase in fruit body production of mushrooms as a result of application of electric pulse. The first one is that the high voltage causes physical damage to the hypha and that stimulates fruit body formation [24]. The other is that some enzymes which result into development of fruit bodies may be activated by the electric pulse stimulation [25].

\section{Conclusion}

This study has established that temperature preference for mycelial growth of SC-1 S. crispa strain is the same 
Table 2. Effect of nitrogen source on mycelial growth of S. crispa.

\begin{tabular}{cc}
\hline Nitrogen Source & Colony Diameter (mm) \\
\hline Alanine & $50.5 \pm 3.3 \mathrm{a}$ \\
Ammonium Acetate & $0.0 \pm 0.0 \mathrm{~d}$ \\
Ammonium Phosphate & $0.0 \pm 0.0 \mathrm{~d}$ \\
Arginine & $0.0 \pm 0.0 \mathrm{~d}$ \\
Calcium Nitrate & $28.9 \pm 4.0 \mathrm{~b}$ \\
Glycine & $54.4 \pm 3.8 \mathrm{a}$ \\
Histidine & $0.0 \pm 0.0 \mathrm{~d}$ \\
Methionine & $5.0 \pm 0.0 \mathrm{~d}$ \\
Potassium Nitrate & $35.0 \pm 3.7 \mathrm{~b}$ \\
Urea & $5.0 \pm 0.0 \mathrm{~d}$ \\
\hline
\end{tabular}

Colony diameter values that do not share a letter are significantly different according to Tukey's test $(\mathrm{p}<0.05)$. The basal medium was composed of $0.05 \mathrm{~g} \mathrm{MgSO}_{4}, 0.46$ g $\mathrm{KH}_{2} \mathrm{PO}_{4}, 1.0 \mathrm{~g} \mathrm{~K}_{2} \mathrm{HPO}_{4}, 120 \mu \mathrm{g}$ thiamine- $\mathrm{HCl}, 20 \mathrm{~g}$ agar and $1000 \mathrm{ml}$ distilled water. Each nitrogen source was added to the basal medium at concentration of 0.02 M. The colony diameter was measured after 28 days of mycelial growth.

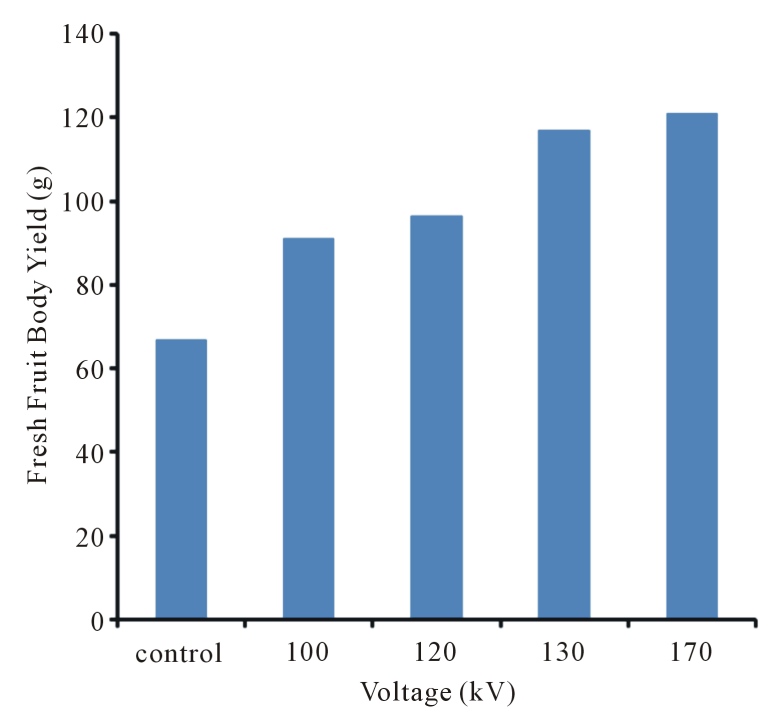

(a)

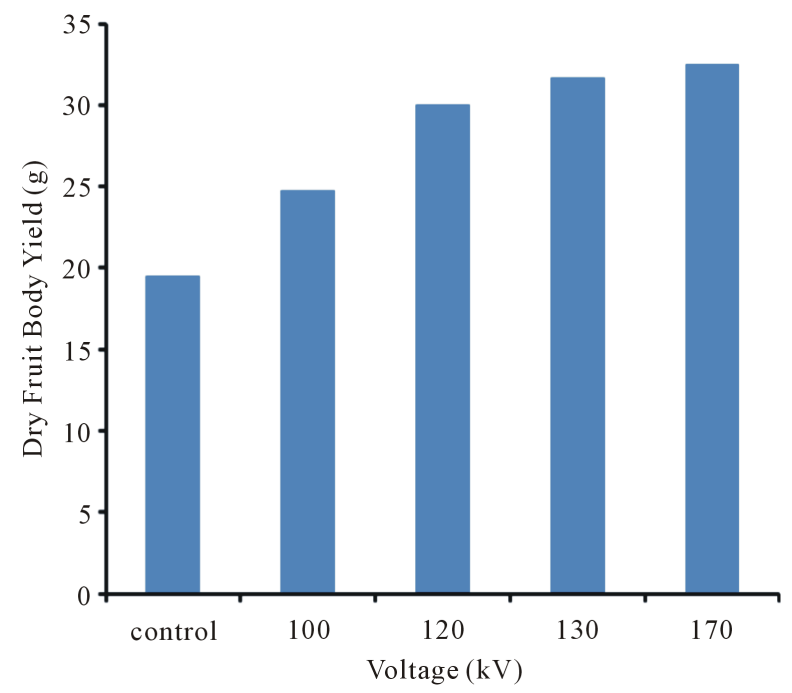

(b)

Figure 5. Effect of electric pulse stimulation on (a) fresh and (b) dry fruit body yields of Sparasia crispa.

as the majority of mushrooms, which is around $25^{\circ} \mathrm{C}$. The best $\mathrm{pH}$ range for vegetative growth of this fungus is 5 - 7. It has been shown that alkaline condition of the medium prior to sterilization is not suitable for this fungus. In case of carbon sources, fructose and glucose showed excellent results. Among nitrogen sources studied, glycine and alanine were found to be most preferred. Results on effect of electric pulse stimulation on fruit body yield of S. crispa have confirmed that fruit body yield of some mushrooms could be increased with application of electric pulse.

\section{References}

[1] Shim, J.-O., Son, S.-G., Yoon, S.-O., Lee, Y.-S., Lee, T.-S., Lee, S.-S., Lee, K.D. and Lee, M.-W. (1998) The Optimal Factors for the Mycelial Growth of Sparassis crispa. The Korean Journal of Mycology, 26, 39-46.

[2] Chang, H.-Y. and Choi, S.-O. (2004) Characteristics of Mycelial Culture of Sparassis crispa. Journal of Mushroom Science and Production, 2, 163-167.

[3] Kimura, T. (2013) Natural Products and Biological Activity of the Pharmacologically Active Cauliflower Mushroom 
Sparassis crispa. Biomedical Research International, 2013, 9 p.

[4] Wang Q.Q., Li, J.M., Wang Y.Q., Zhang, X.Z. and Li K.Z. (2011) Comparison of Aromatic Components from Sparassis crispa Extracted by Static Headspace and Headspace-SPME. Journal of Life Sciences, 17, 174-176.

[5] Yoshikawa, K., Kokudo, N., Hashimoto, T., Yamamoto, K., Inose, T. and Kimura, T. (2010) Novel Phthalide Compounds from Sparassis crispa (Hanabiratake), Hanabiratakelide A-C, exhibiting Anticancer Related Activity. Biological and Pharmaceutical Bulletin, 33, 1355-1359. http://dx.doi.org/10.1248/bpb.33.1355

[6] Kwon, A.H., Qiu, Z., Hashimoto, M., Yamamoto, K. and Kimura, T. (2009) Effects of Medicinal Mushroom (Sparassis crispa) on wound Healing in Streptozotocin-Induced Diabetis Rats. The American Journal of Surgery, 197, 503509. http://dx.doi.org/10.1016/j.amjsurg.2007.11.021

[7] Yamamoto, K., Kimura, T., Sugitachi, A. and Matsuura, N. (2009) Anti-Angiogenic and Anti-Metastatic Effects of Beta-1,3-D-Glucan Purified from Hanabiratake, Sparassis crispa. Biological \& Pharmaceutical Bulletin, 32, 503-509.

[8] Harada, T., Miura, N.N., Adachi, Y., Nakajima, M., Yadomae, T. and Ohno, N. (2003) Antibody to Soluble 1,3/1,6-bD-Glucan, SCG in Sera of Naive DBA/2 Mice. Biological and Pharmaceutical Bulletin, 26, 1225-1228. http://dx.doi.org/10.1248/bpb.26.1225

[9] Tsukamoto, S., Maeda, T., Ikeda, M. and Akiyama, H. (2003) Application of Pulsed Power to Mushroom Culturing. Proceeding of 14th IEEE International Pulsed Power Conference, Dallas, 15-18 June 2003, 1116-1119.

[10] Tsukamoto, S., Kudoh, H., Ohga, S., Yamamoto, K. and Akiyama, H. (2005) Development of an Automatic Electrical Stimulator for Mushroom Sawdust Bottle. Proceeding of 15th IEEE International Pulsed Power Conference, Monterey, 11-13 June 2005, 1437-1440.

[11] Islam, F. and Ohga, S. (2012) The Response of Fruit Body Formation on Tricholoma matsutake in Situ Condition by Applying Electric Pulse Stimulator. ISRN Agronomy, 2012, Article ID: 462724.

[12] Chioza, A. and Ohga, S. (2013) Mycelial Growth of Paecilomyces hepiali in Various Agar Media and Yield of Fruit Bodies in Rice Based Media. Advances in Microbiology, 3, 529-536. http://dx.doi.org/10.4236/aim.2013.37071

[13] Chi, J.H., Ha, T.M., Kim, Y.H. and Rho, Y.D. (1996) Studies on Main Factors Affecting the Mycelial Growth of Phellinus linteus. Korean Journal of Mycology, 24, 214-222.

[14] Shim, S.M., Lee, K.R., Kim, S.H., Im, K.H., Kim, J.W., Lee, U.Y., Shim, J.O., Lee, M.W. and Lee, T.S. (2003) The Optimum Culture Conditions Affecting the Mycelial Growth and Fruiting Body Formation of Paecilomyces fumosoroseus. Mycobiology, 31, 214-220. http://dx.doi.org/10.4489/MYCO.2003.31.4.214

[15] Imtiaz, A., Lee, T.-S. and Ohga, S. (2010) Exploration on Filamentous Phenotype of Coprinus comatus Collected from Different Ecological Origins. Journal of the Faculty of Agriculture Kyushu University, 55, 203-207.

[16] Lee, I.-K., Shim, H.-J. Woo, S.-D. Je, Y.-H., Yang, Z. and Kang, S.-K. (1999) Variation in Growth and Pathogenicity of Beauveria brassiana and Paecilomyces fumosoroseus Pathogenicity to the Pine Gall Midge, Thecodiplosis Japanese. Korean Journal of Applied Microbiology and Bioengineering, 27, 415-418.

[17] Sung, G., Shrestha, B., Han, S. and Sung, J. (2011) Cultural Characteristics of Ophiocordyceps heteropoda Collected from Korea. Mycobiology, 39, 1-6. http://dx.doi.org/10.4489/MYCO.2011.39.1.001

[18] Sung, G., Shrestha, B., Han, S., Kim, S. and Sung, J. (2010) Growth and Cultural Characteristics of Cordyceps cardinalis Collected from Korea. Mycobiology, 38, 274-281. http://dx.doi.org/10.4489/MYCO.2010.38.4.274

[19] Cheong, J.-C., Park, J.-S., Hong, I.-P., Seok, S.-J., Jhung, C.-S. and Lee, C.-J. (2008) Cultural Characteristics of Cauliflower Mushroom, Sparassis crispa. Korean Journal of Mycology, 36, 16-21.

[20] Moonmoon, M., Uddin, M.N., Khan, A.S. and Amin, S.M.R. (2008) Effect of Culture Media and Environmental Factors on the Mycelial Growth of Volvariella volvacea. Bangladesh Journal of Mushroom, 2, 33-42.

[21] Shim, S.M., Oh, Y.H., Lee, K.R., Kim, S.H., Im, K.H., Kim, J.W., Lee, U.Y., Shim, J.O., Shim, M.J., Lee, M.W., Ro, H.S., Lee, H.S. and Lee, T.S. (2005) The Characteristics of Cultural Conditions for the Mycelial Growth of Macrolepiota procera. Mycobiology, 33, 15-18. http://dx.doi.org/10.4489/MYCO.2005.33.1.015

[22] Kibar, B. and Peksen, A. (2011) Nutritional and Environmental Requirements for Vegetative of Edible Ectomycorrhizal Mushroom Tricholoma terreum. Zemdirbyste-Agriculture, 98, 409-414.

[23] Takaki, K., Yamaguchi, R., Kusaka, T., Kofujita, H., Takahashi, K., Sakamoto, Y., Narimatsu, M. and Nagane, K. (2010) Effects of Pulse Voltage Stimulation on Fruit Body Formation in Lentinula edodes Cultivation. Seventh International Symposium on Non-Thermal/Thermal Plasma Pollution Control Technology \& Sustainable Energy, ISNTP-7, Canada, June 2010.

[24] Kudo, S., Mitobe, S. and Yoshimura, Y. (1999) Electric Stimulation Multiplication of Lentinulus edodes. Journal of the Institute of Electrostatics Japan, 23, 186-190.

[25] Jitsufuchi, Y. and Yamamoto, M. (1987) Research for Improvement of Lentinula edodes Cultivation: Application of Electric Stimulation for Mushroom Cultivation (in Japanese). Kyushu Electrical Co., Fukuoka. 